\title{
Nicotiana glauca (Tree Tobacco) Intoxication-Two Cases in One Family
}

\author{
Victoria Furer • Moshe Hersch • Noa Silvetzki • \\ Gabriel S. Breuer • Shoshana Zevin
}

Published online: 22 July 2010

(C) American College of Medical Toxicology 2010

\begin{abstract}
We present two cases of rare human poisoning in one family following ingestion of cooked leaves from the tobacco tree plant, Nicotiana glauca. The toxic principle of $N$. glauca, anabasine (C10H14N2), is a small pyridine alkaloid, similar in both structure and effects to nicotine, but appears to be more potent in humans. A 73-year-old female tourist from France, without remarkable medical history, collapsed at home following a few hours long prodrome of dizziness, nausea, vomiting, and malaise. The symptoms developed shortly after eating $N$. glauca cooked leaves that were collected around her daughter's house in Jerusalem and mistaken for wild spinach. She was found unconscious, with dilated pupils and extreme bradycardia. Following resuscitation and respiratory support, circulation was restored. However, she did not regain consciousness and died 20 days after admission because of multi-organ failure. Anabasine was identified by gas chromatography/mass spectrometry method in $N$. glauca leaves and in the patient's urine. Simultaneously, her 18-year-old grandson developed weakness and myalgia after ingesting a smaller amount of the
\end{abstract}

V. Furer $(\bowtie) \cdot$ N. Silvetzki $\cdot$ S. Zevin

Medicine Division, Department of Internal Medicine B,

Shaare Zedek Medical Center,

12 Bayit Street,

Jerusalem 91031, Israel

e-mail: vikushf@gmail.com

\section{Hersch}

Intensive Care Unit, Shaare Zedek Medical Center,

12 Bayit Street,

Jerusalem 91031, Israel

\section{G. S. Breuer}

Medicine Division, Department of Internal Medicine A, Shaare Zedek Medical Center,

12 Bayit Street,

Jerusalem 91031, Israel same meal. He presented to the same emergency room in a stable condition. His exam was remarkable only for sinus bradycardia. He was discharged without any specific treatment. He recovered in $24 \mathrm{~h}$ without any residual sequelae. These cases raise an awareness of the potential toxicity caused by ingestion of tobacco tree leaves and highlight the dangers of ingesting botanicals by lay public. Moreover, they add to the clinical spectrum of $N$. glauca intoxication.

Keywords Nicotiana glauca $\cdot$ Tobacco tree $\cdot$ Nicotine . Anabasine $\cdot$ Poisoning $\cdot$ Gas chromatography .

Mass spectrometry

\section{Introduction}

Nicotine is a pyridine alkaloid derived from the tobacco plant (Solanacea family, Nicotiana genus). First identified in 1826, it is named after Jean Nicot (1530-1600), a French diplomat, who is believed to have introduced snuffpowdered tobacco to Europe. Nicotiana glauca Grah, also known as wild tobacco or tree tobacco, is a multi-branched perennial shrub of up to $5 \mathrm{~m}$ high with smooth green hairless branches, glaucous leaves, and tubular yellow flowers (Fig. 1) [1]. Glauca was derived from the Greek meaning "bluish-gray", referring to the powdery coating on this plant. Leaves of the N. glauca are large, alternate, ovate, and blue-green in color with a powdery coating, and are smoked for ritual purposes by Navajo Indians. $N$. glauca is indigenous to South America. It has been widely introduced and naturalized in the warm dry climates, and has become a weed plant in Arizona, California, Texas, Mexico, Hawaiian Islands, the Mediterranean region, and Australia. In Israel, the plant is found along walls, on debris or growing along sandy areas. 


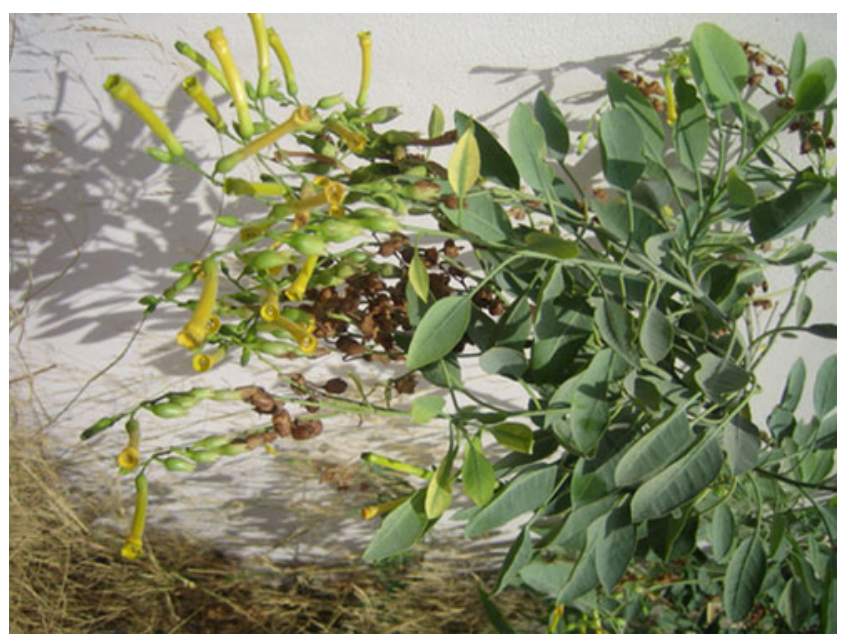

Fig. 1 A structural nicotine analog

Species in the genus Nicotiana are characterized by the presence of pyridine alkaloids in leaf and root tissues, the four most abundant being nicotine, nornicotine, anabasine, and anatabine [2]. Anabasine $\left(\mathrm{C}_{10} \mathrm{H}_{14} \mathrm{~N}_{2}\right)$, a structural nicotine analog (Fig. 2 ), constitutes a significant proportion $(98 \%)$ of the alkaloids in only a few species, among them $N$. glauca $[2,3]$. Its content varies among various parts of the plant, being highest in the leaves and the bark. This highly toxic alkaloid is responsible for the clinical toxicology of the plant: teratogenic effects caused by consumption of $N$. glauca in animals [4-7] and either severe [8-13] or fatal poisoning in humans $[8,12,14-16]$. In most of these cases the patients mistook the plant for an edible green (such as marog-Amaranthus hybridus, Amranthaceae, spinach-Spinacia oleracea, or pokeweedPhytolacca americana).

Anabasine is a nicotinic receptor agonist that exerts its clinical effect primarily by binding to nicotinic acetylcholine receptors at the neuromuscular junction, autonomic ganglia and brain. It is less potent compared with (-) nicotine based on in vitro and animal studies $[17,18]$. In $N$. glauca, anabasine exists as a racemic mixture of $\mathrm{S}$ and $\mathrm{R}$ enantiomers, with $\mathrm{R}$-anabasine being somewhat more potent compared with S-anabasine [19]. Anabasine was also found to be a weak inhibitor of acetylcholinesterase $\left(I_{50}\right.$ of $\left.1,000 \mu \mathrm{M}\right)$ [20]; however, the main clinical<smiles>c1cncc(C2CCCCN2)c1</smiles>

Anabasine<smiles>CN1CCCC1c1cccnc1</smiles>

Nicotine effects of its toxicity are caused by neuromuscular blockade [9].

We report two cases of the rare human poisoning by ingested cooked tobacco tree leaves in one family, confirmed by gas chromatography/mass spectrometry analysis, and discuss the difference in clinical manifestations and the time course in both cases. Literature review of 16 cases of $N$. glauca intoxication is provided to better characterize the time course, clinical presentation, and outcomes of this uncommon intoxication.

\section{Case 1}

A 73-year-old female tourist from France born in Algeria, without any remarkable medical history, came to visit her daughter's family in Jerusalem, Israel. The family was living in a new neighborhood with building debris around the house. Upon her arrival, she found green shrubs with glaucous leaves around the neighborhood that she mistook for spinach. She collected the leaves and cooked a dish according to the recipe that she recalled from her childhood. Approximately $30 \mathrm{~min}$ following the meal, she complained of being unwell and said to her family that she might have food poisoning. She vomited several times and went to rest. Vomiting recurred $90 \mathrm{~min}$ later, followed by loss of consciousness. In a few minutes, a neighbor physician started cardiopulmonary resuscitation (CPR). He reported that on his exam the patient was unconscious, gasping, central pulse was 30 beats/min, and she had dilated pupils. A paramedic team that arrived 5 min later reported that the patient was not breathing, and no pulse was palpated. Cardiac monitor showed pulseless electrical activity. The patient was cyanotic, and her periphery was cold. The patient was intubated. Following advanced cardiac life support for 5 min that included repeated administration of adrenaline and atropine, she had restored systolic blood pressure of $100 \mathrm{mmHg}$ and sinus rhythm on monitor. The patient was transferred to Shaare Zedek Medical Center, Jerusalem. On examination at the Emergency Department (ED), the patient remained unconscious and unresponsive to painful stimuli. She was intubated and ventilated, her blood pressure was $125 / 75 \mathrm{mmHg}$, PR 80 beats $/ \mathrm{min}$, and temperature was $35.7^{\circ} \mathrm{C}$. The pupils were dilated and unresponsive. There were no localizing signs on neurological exam. There was no muscle fasciculation. The rest of the physical exam revealed bi-basilar inspiratory crackles, regular heart sounds, soft abdomen without organomegaly, and no peripheral edema. Initial laboratory blood work up at the ED showed complete blood count remarkable for leukocytosis (WBC 19,000/ $\mu$, polymorphonuclears $68 \%$ ), along with normal electrolytes and renal panel (Na $139 \mathrm{mEq} / \mathrm{L}, \mathrm{K} 3.6 \mathrm{mEq} / \mathrm{L}, \mathrm{BUN} 18 \mathrm{mg} /$ $\mathrm{dL}$, creatinine $0.8 \mathrm{mg} / \mathrm{dL}$ ). Arterial blood gas analysis was notable for combined metabolic and respiratory acidosis

Fig. 2 Chemical structures of anabasine and nicotine 
(pH 7.11, pCO2 60 mmHg, pO2 64 mmHg, $\mathrm{HCO} 315 \mathrm{mEq} /$ L). Creatine phosphokinase was mildly elevated (238 IU/L). Liver enzymes drawn about $4 \mathrm{~h}$ later were significantly elevated (aspartate aminotransferase (AST) $821 \mathrm{IU} / \mathrm{L}$, alanine aminotransferase (ALT) $569 \mathrm{IU} / \mathrm{L}$, lactate dehydrogenase (LDH; 4,300 IU/L). Within $24 \mathrm{~h}$, a downtrend of liver enzymes was observed (AST declined to $152 \mathrm{IU} / \mathrm{L}$, ALT to 238 , and $\mathrm{LDH}$ to 1,160$)$. Urinary toxicology screen was negative. To exclude digitalis intoxication, digoxin plasma level was obtained and found to be negative. Chest X-rays demonstrated a diffuse infiltrate in the right lung, consistent with aspiration. Head computed tomography did not reveal any focal finding. On the first hospitalization day, the patient's family gathered a sample of the culprit plant and it was taken to the Botanical Department at the Hebrew University in Jerusalem. A botanist had identified the plant as $N$. glauca. To confirm anabasine-induced intoxication, the leaves of the plant and patient's urine sample were sent to gas chromatography/mass spectrometry analysis that eventually confirmed significant anabasine content in both specimens. The patient did not regain consciousness because of anoxic brain damage. She died 20 days after admission because of infectious complications and multi-organ failure.

\section{Case 2}

Simultaneously, an 18-year-old grandson of the aforementioned patient developed general weakness and myalgia a few hours after ingesting a smaller amount of the same meal. He presented to the same ED in a stable condition. He was afebrile. His physical exam was remarkable only for sinus bradycardia (50 beats/min). Blood work up was not performed. He was discharged without any specific treatment. He reported dizziness, fatigue, and headache that had resolved spontaneously in $24 \mathrm{~h}$ without any residual sequellae.

\section{Discussion}

N. glauca is atypical within the genus Nicotiana, in that anabasine $\left(\mathrm{C}_{10} \mathrm{H}_{14} \mathrm{~N}_{2}\right)$ rather than nicotine is predominant as the main component of its leaf pyridine alkaloid fraction [2, 3]. Anabasine has been identified as the responsible teratogen of $N$. glauca in animals [4-7] and poisoning agent in humans [8-16]. Poisoning by anabasine is characterized by nicotine-like toxicity. The clinical effects of nicotine alkaloid toxicity are the result of the summation of actions at ganglionic sites, motor end plates, and smooth muscle [17, 18, 21-23]. Nicotine alkaloids initially stimulate the ganglia of the sympathetic and parasympathetic nervous systems by direct cholinomimetic action on the ganglia. This is quickly followed by prolonged ganglionic blockage due to persistent depolarization. A similar action occurs at the neuromuscular junction causing total paralysis of skeletal muscles and subsequent respiratory failure. The CNS is affected initially by stimulation, resulting in tremors and convulsions, progressing to depression. Death occurs from respiratory failure due to peripheral blockage of the muscles of respiration. Vomiting is a result of stimulation of the emetic chemoreceptor trigger zone [10]. Additionally, patients exposed to substantial amounts of nicotine alkaloid may have tachycardia and hypertension. Cardiovascular collapse can follow the hypertension depending on the degree of toxic exposure [18]. Stimulation of sympathetic ganglia and the adrenal medulla combined with discharge of catecholamines from sympathetic nerve endings and chromaffin tissues of different organs are postulated to be responsible for the cardiovascular signs.

High-performance liquid chromatography/photodiode array/mass spectrometry (HPLC/PDA/MS) has been used to detect and quantify anabasine [12, 14-16]. Based on postmortem analysis of blood nicotine and anabasine concentrations in the fatal poisoning cases in humans, anabasine was suggested to be more toxic compared with nicotine. The blood concentration of anabasine found in a fatally poisoned young man was $1.15 \mathrm{mg} / \mathrm{L} \mathrm{[14]} \mathrm{and} 2.2 \mathrm{mg} / \mathrm{L}$ in a 43 -yearold male who died after an apparent ingestion of $N$. glauca water extract [15]. Tissue levels of anabasine detected in the former fatal case [14] were as following: urine, $73.8 \mathrm{mg} / \mathrm{L}$; kidney, $15.8 \mathrm{mg} / \mathrm{kg}$; brain, $11.0 \mathrm{mg} / \mathrm{kg}$; lung, $10.5 \mathrm{mg} / \mathrm{kg}$; heart, $10.4 \mathrm{mg} / \mathrm{kg}$; and gastric contents, $113.4 \mathrm{mg} / \mathrm{L}$. In comparison, the reported fatal ingestions of nicotine doses of 10 to $25 \mathrm{~g}$ were associated with blood concentrations ranging from 11 to $63 \mathrm{mg} / \mathrm{L}$ [24].

The onset of symptoms in an acute nicotine alkaloid poisoning is usually rapid, within $15-30$ min of ingestion and the symptoms often follow a biphasic pattern with initial vomiting and adrenergic stimulation followed by symptoms of ganglionic and neuromuscular blockage [22, 23]. The present case is consistent with this pattern of nicotinic intoxication with vomiting and dizziness developing $30 \mathrm{~min}$ after ingestion, followed by a respiratory arrest after about $90 \mathrm{~min}$. There is no antidote for nicotinic cholinergic poisoning, and the treatment is largely supportive and symptomatic $[17,18]$.

There are very few reports in the literature of verified $N$. glauca toxicity in humans. One possible explanation for the small number of the reports is that most cases of mild poisoning do not present to a medical attention, whereas others could have been underdiagnosed and/or underreported. The available details from all the published case reports have been summarized in Table 1 .

Our cases and an analysis of the published literature demonstrate several key features in the presentation of $N$. glauca poisoning. In the majority of the cases, the victims seemed to misidentify the plant for another familiar edible 


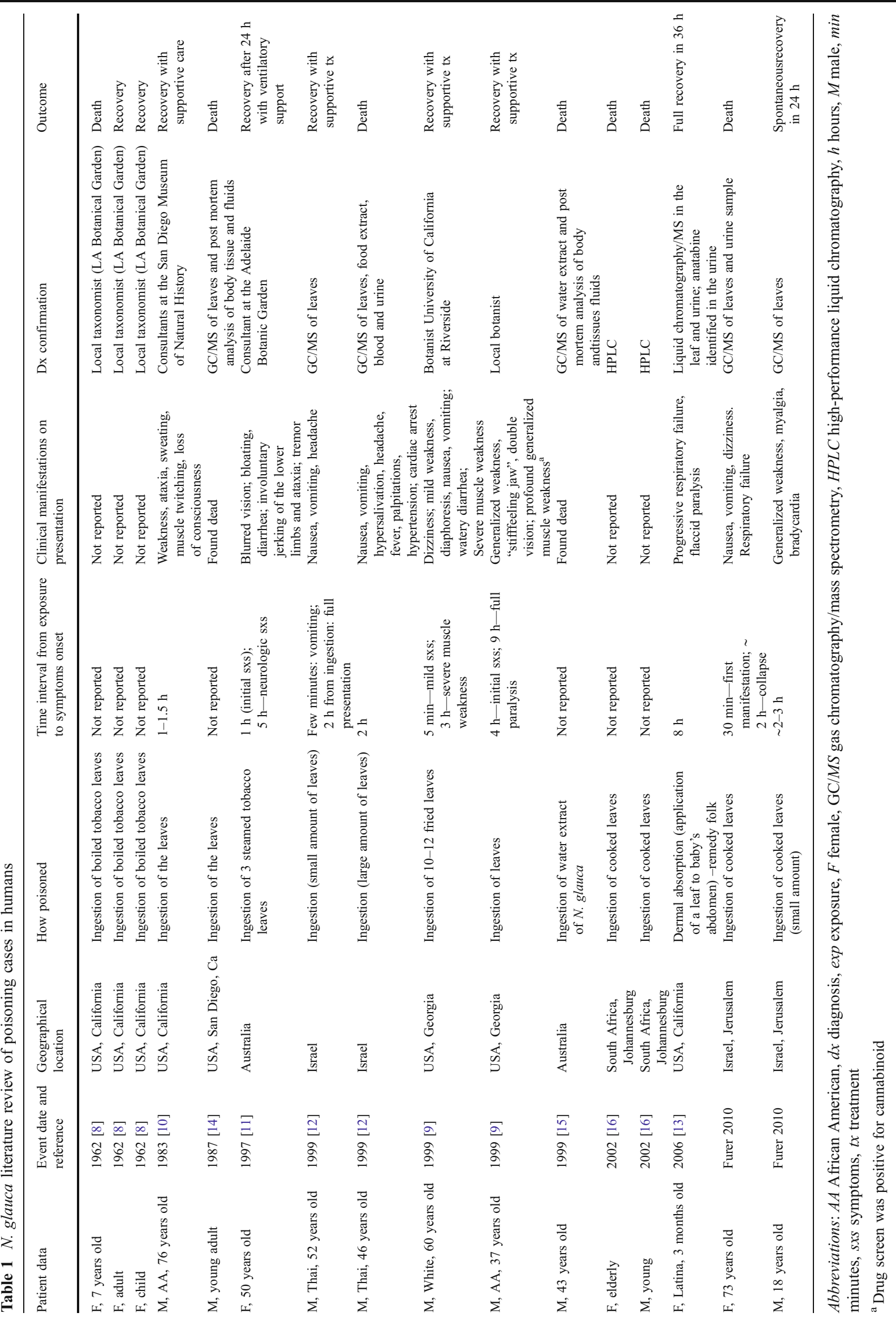


green. Toxicity had mainly resulted from anabasine ingestion that was confirmed in nine cases by HPLC/PDA/MS methods [12-16]. However, our review implies a key role for the botanist's support that allowed a quick and reliable identification of the leaves morphology and therefore diagnosis. Importantly, one pediatric case of a topical application of the tobacco tree leave as a folk remedy demonstrated that anabasine toxicity can result from dermal exposure and absorption in addition to gastric absorption [13].

The onset of symptoms ranged from $5 \mathrm{~min}$ to $3 \mathrm{~h}$ after ingestion. Out of 15 reported cases, seven resulted in death. The symptoms ranged from nausea, vomiting, palpitations and weakness to muscle paralysis, cardiovascular collapse, and respiratory failure.

Remarkably, elevated liver enzymes (AST, ALT, and LDH) drawn about $6 \mathrm{~h}$ after arrest were observed in our first case. Given a disproportional elevation of LDH compared with AST and ALT, and a significant downtrend of the enzymes within $24 \mathrm{~h}$, these abnormalities were interpreted as ischemic hepatitis rather than direct anabasine hepatotoxicity. Supporting this notion, no evidence of hepatotoxicity was found in three other cases that had recovered from anabasine intoxication [9-11]. Autopsy findings in a fatal case caused by $N$. glauca ingestion revealed essentially normal internal organs, except for a minor nonspecific focal polymorph infiltrate in the liver [15].

The cases we described demonstrate a variability of clinical presentation from mild symptoms to fatal outcome, probably due to a difference in the ingested amount of the poisonous plant. Importantly, limitations of our second case should be noted. Whereas history of $N$. glauca leaves ingestion by the grandson seemed to be reliable, it was not confirmed by testing of gastric content or tissues anabasine level. Non-specific clinical manifestations (such as general weakness, myalgia, and sinus bradycardia) might represent other medical conditions, such as a psychosomatic response to observing a close family member unexpected collapse. Therefore, no definitive conclusion regarding the dose dependent effect of $N$. glauca induced intoxication can be drawn from our cases.

\section{Conclusion}

Ingestion of $N$. glauca leaves or their extract has a toxic potential. The toxicity is mediated by nicotine-like alkaloid, anabasine. This poisoning should be included in the differential diagnosis of sudden onset of muscle paralysis and respiratory arrest.

Acknowledgements We gratefully acknowledge the Mass Spectrometry Unit/Police Headquarters and the Institute of Clinical Toxicology and Pharmacology, Sheba Medical Center, for their contribution in the leaves and urine sample analysis.

\section{References}

1. United States Department of Agriculture National Resources Conservation Service. Available at: http://plants.usda.gov. Accessed January 10, 2010

2. Saitoh F, Kawasima N (1985) The alkaloid contents of sixty Nicotiana species. Phytochemistry 24:477-480

3. Sinclair SJ, Murphy KJ, Birch CD, Hamill JD (2000) Molecular characterization of quinolinate phosphoribosyltransferase (QPRtase) in Nicotiana. Plant Mol Biol 44:603-617

4. Keeler RF, Crowe MW (1984) Teratogenicity and toxicity of wild tree tobacco, Nicotiana glauca in sheep. Cornell Vet 74:50-59

5. Keeler RF, Crowe MW, Lambert EA (1984) Teratogenicity in swine of the tobacco alkaloid anabasine isolated from Nicotiana glauca. Teratology 30:61-69

6. Plumlee KH, Holstege DM, Blanchard PC et al (1993) Nicotiana glauca toxicosis of cattle. J Vet Diagn Invest 5:498-499

7. Panter KE, James LF, Gardner DR (1999) Lupines, poisonhemlock and Nicotiana spp. toxicity and teratogenicity in livestock. J Nat Toxins 8:117-134

8. Anonymous (1962) Child's death laid to wild tobacco. Los Angeles Times. June 10; B-8

9. Mellick LB, Makowski T, Mellick GA, Borger R (1999) Neuromuscular blockade after ingestion of tree tobacco (Nicotiana glauca). Ann Emerg Med 34:101-104

10. Manoguerra AS, Freeman D (1982) Acute poisoning from the ingestion of Nicotiana glauca. J Toxicol Clin Toxicol 19:861-864

11. Webb M, Dalzel S (1997) Nicotiana glauca toxicity. Emerg Med 9:25-28

12. Mizrachi N, Levy S, Goren ZQ (2000) Fatal poisoning from Nicotiana glauca leaves: identification of anabasine by gaschromatography/mass spectrometry. J Forensic Sci 45:736-741

13. Murphy NG, Albin C, Tai W, Benowitz NL (2006) Anabasine toxicity from a topical folk remedy. Clin Pediatr (Phila) 45:669-671

14. Castorena JL, Garriott JC, Barnhardt FE, Shaw RF (1987) A fatal poisoning from Nicotiana glauca. J Toxicol Clin Toxicol 25:429435

15. Sims DN, James R, Christensen T (1999) Another death due to ingestion of Nicotiana glauca. J Forensic Sci 44:447-449

16. Steenkamp PA, van Heerden FR, van Wyk BE (2002) Accidental fatal poisoning by Nicotiana glauca: identification of anabasine by high performance liquid chromatography/photodiode array/ mass spectrometry. Forensic Sci Int 127:208-217

17. Sloan JW, Martin WR, Bostwick M, Hook R, Wala E (1988) The comparative binding characteristics of nicotinic ligands and their pharmacology. Pharmacol Biochem Behav 30:255-267

18. Kem WR, Mahnir VM, Papke RL, Lingle CJ (1997) Anabaseine is a potent agonist on muscle and neuronal alphabungarotoxin-sensitive nicotinic receptors. J Pharmacol Exp Ther 283:979-992

19. Lee ST, Wildeboer K, Panter KE et al (2006) Relative toxicities and neuromuscular nicotinic receptor agonistic potencies of anabasine enantiomers and anabaseine. Neurotoxicol Teratol 28:220-228

20. Karadsheh N, Kussie P, Linthicum DS (1991) Inhibition of acetylcholinesterase by caffeine, anabasine, methyl pyrrolidine and their derivatives. Toxicol Lett 55:335-342

21. Pappano AJ (2007) Cholinoceptor-activating and cholinesterase inhibiting drugs, 10th edn. McGraw-Hill, Boston, MA

22. Zevin S, Gourlay SG, Benowitz NL (1998) Clinical pharmacology of nicotine. Clin Dermatol 16:557-564

23. Schep LJ, Slaughter RJ, Beasley DM (2009) Nicotinic plant poisoning. Clin Toxicol (Phila) 47:771-781

24. Baselt RC, Cravey RH (1995) Disposition of toxic drugs and chemicals in man, 4th edn. Chemical Toxicology Institute, Foster City, $\mathrm{Ca}$ 